\title{
Discriminating Faults from Power Swing Using Impedance Angle and Analysis in Three Dimensional Space
}

\author{
Aldrich Zeno*, Jordan Rel Orillaza \\ University of the Philippines Diliman, Quezon City, Philippines. \\ * Corresponding author. Tel.: +63-9277607642; email: aldrichzeno@rocketmail.com \\ Manuscript submitted September 17, 2018; accepted January 8, 2019. \\ doi: 10.17706/ijcee.2019.11.1.27-40
}

\begin{abstract}
Faults lead to de-energising of a section of transmission line thus decreasing the reliability of the system. Power swing affects the distance relays leading to false alarms which were the leading cause of unreliability. Faults cause permanent movement of the operating point in RX plot with a transient oscillation. The locus of power swing forms closed loops. Here, impedance angles were used to discriminate the faults from power swing. The investigation was carried out along with three dimensional plots to visualize the locus of impedance in resistance, reactance and time axis. Results signify that faults were differentiated from power swing using differential impedance angle. The test cases include all the unbalanced faults as well as an unstable swing. Power swing formed bi-conical loops above and below the ideal operating impedance, while differential impedance formed hyperboloid with the mean impedance being zero. Simulations were carried out in a 2 bus system and all the voltages and currents were extracted from the center of transmission line. Visual representation of normal operating impedances and power swing using three dimensional plots $(\mathrm{R}-\mathrm{X}-\mathrm{t}$ space) and $(\mathrm{dR} / \mathrm{dt}-\mathrm{dX} / \mathrm{dt}-\mathrm{t}$ space) were shown in the Appendix.
\end{abstract}

Key words: Faults, impedance angle, power swing, R-X-t space, dR/dt-dX/dt-t space.

\section{Introduction}

Electrical networks have expanded tremendously in the last few decades making them one of the complex systems in the world. With complexity arose the susceptibility to failures. The most occurring events in the power system are faults and power swings. Faults cause the relays to isolate the network in order to protect the components connected to the network. Isolation of network leads to loss of power and reduction in reliability.

Power swings are caused due to disturbances in network. The disturbance could be making/breaking operation of circuit breaker or loss/addition of large unit in the system which could be generator or transmission line or load. Power swing caused significant damage in the past. Some of them include US blackout on 14 August 2003 affecting 55 million [1] and blackout in India affecting 600 million on July 2012 [2]. Misfiring of relays in absence of fault due to power swing had caused significant loss in revenue. Absence of power can bring the whole nation to a standstill thus crippling the economic performance.

Some of the methods used to distinguish fault from a power swing and setting relay to operate only for faults include: two blinder scheme [3]; elliptical trajectory of Z [4]; R-Rdot method [5]; and admittance plots [6]. They revolve around static R-X plane independent of time. The detection involves fewer 
computations and were robust. They possess areas of operation and areas of restraining depending on the locus of $\mathrm{Z}$ in respective planes (R-X plane, G-B plane, R-Rdot plane). Transform techniques like symmetrical component analysis [7]; prony's method [8]; fourier transform [9]; wavelet transforms [10]; and modal analysis [11]; involve huge computations and were dependant on initial values for convergence. The simplification done in evaluating the magnitudes of each frequency was compensated by the accuracy and time required for transforming from time domain to frequency domain. The other innovative methodologies involve, Taylor series expansion using error estimation [12]; usage of negative sequence components in evaluating negative sequence apparent power [13]; evaluation of a power swing and fault using index by using voltage angle and active power flows [14]; Lissajous figures obtained from voltages and currents signals [15]; differences observed in the phase angles of currents [16]; and usage of differential power coefficients which estimates the difference in predicted and actual power flows leading to identification of fault [17].

The proposed method uses impedance angle and rate of change of impedance angle which is similar to R-Rdot [5] and differences observed in impedance angles to indicate the type of fault similar to observing phase angles of currents [16]. Since power system is a dynamically varying entity, it is vital to understand the locus of impedances in time domain; especially during faults and power swing.

\section{Methodology}

Faults change the operating point of the impedance and cause sudden permanent shift in impedance. Power swing can have changes in amplitude depending on the intensity of the disturbance; and changes in swinging frequency depending on network parameters. Since fault is a fast phenomenon and power swings are slow, rate of change of impedance will cause immediate changes for faults, while the power swing will oscillate along operating point.

The equations used for evaluating the line to ground impedances were as shown below [18].

$$
\begin{aligned}
& Z a\left\llcorner\theta=\frac{V a}{I_{a}+k I_{o}}\right. \\
& I o=\frac{I a+I b+I c}{3} \\
& \frac{d \theta}{d t}=\frac{\theta_{i}-\theta_{i-1}}{t_{i}-t_{i-1}}
\end{aligned}
$$

where,

$V a$ and $I a$ are voltages and currents in phase A.

$k$ is the sensitivity factor for zero sequence current

Io is the zero sequence current.

$i$ is the present sample.

$i-1$ is the previous sample

$Z a$ was used to understand the locus of impedance during faults and power swings, while $\theta$ was used for differentiating faults from power swings.

Equation 3 indicates the differential impedance which was used for discriminating a fault from power swing. Faults vary quickly and power swings vary slowly. Thus, this equation can even detect a fault during power swing and trips only for fault. The faults were tested in the presence of power swing.

\section{Simulations}

Test system was a 2 bus system built in matlab/simulink consisting of generator, transmission line and load. All the measurements for voltages and currents were taken from the midpoint of transmission line. 
The system is shown in the Fig. 1.

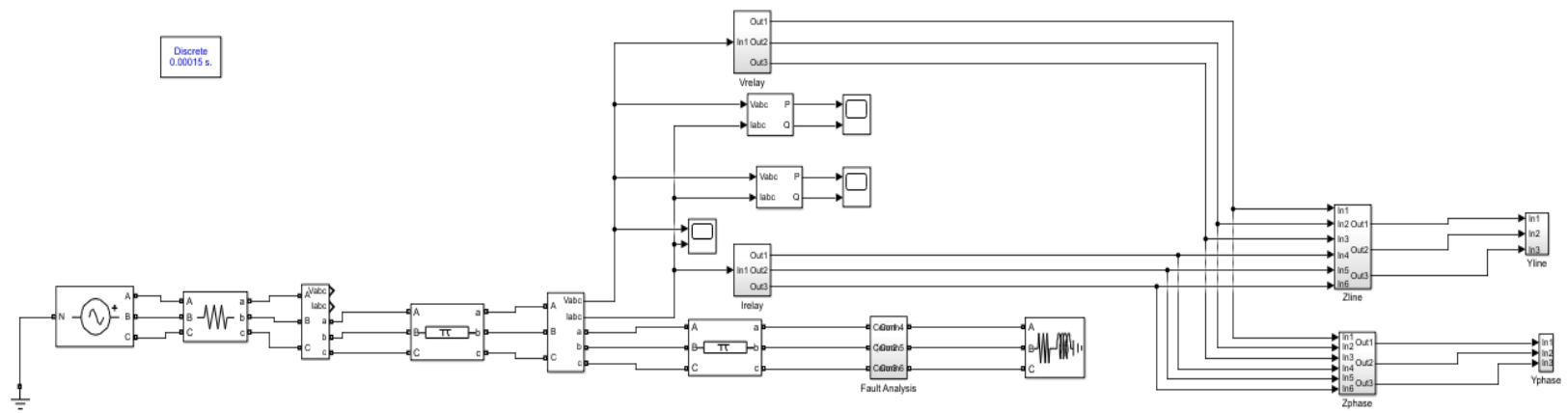

Fig. 1. Test system for simulation.

The generator generates both swinging frequency and power frequency. The high tension wire used was a $735 \mathrm{kV}$ line possessing three bundles of 4-Bersfort ACSR 1355 MCM conductors with two and half inch diameter steel ground wires. Total length of transmission line was $200 \mathrm{~km}$. This configuration yielded a surge impedance of $255 \mathrm{ohm}$ accounting to surge impedance loading of 2200MVA. The load used for testing operates at a lagging power factor of 0.95 and 2200MVA loading. A source resistance of $0.001 \mathrm{ohms}$ was used for convergence during simulation.

Power swing was injected into the system which has amplitude variation of $(\mathrm{V} \pm 0.8 \mathrm{pu})$. Since the RMS line voltage of the system is $735 \mathrm{kV}$. Thus the peak line voltage will be $735^{*} \sqrt{2}$ which is $1039.45 \mathrm{kV}$. By evaluating peak phase voltage $1039.45 / \sqrt{3}$ we get $600 \mathrm{kV}$ which will be considered as $1 \mathrm{pu} . \pm 0.8 \mathrm{pu}$ variation of $600 \mathrm{kV}$ will yield a swinging in from $120 \mathrm{kV}$ to $1080 \mathrm{kV}$. Since fast swings (5 to $10 \mathrm{~Hz}$ ) were considered to be the reason for misoperation of relays [19], the frequency used for injecting power swing is $10 \mathrm{~Hz}$.

\subsection{Faults}

The faults simulated are line to ground (LG), line to line (LL), open line or open conductor (OL) and high impedance (HI) fault. The green colored transparent plane observed in three dimensional plots indicates the instant of fault which is at $0.5 \mathrm{~s}$. The transparent plane gives simultaneous understanding of $\mathrm{R}$ and $\mathrm{X}$ at the instant of fault during power swing.

\subsubsection{Line to ground fault}

Line to Ground (LG) fault was given at the load end of transmission line from $0.5 \mathrm{~s}$ to $1 \mathrm{~s}$. The voltages and currents are shown in the Fig. 2.

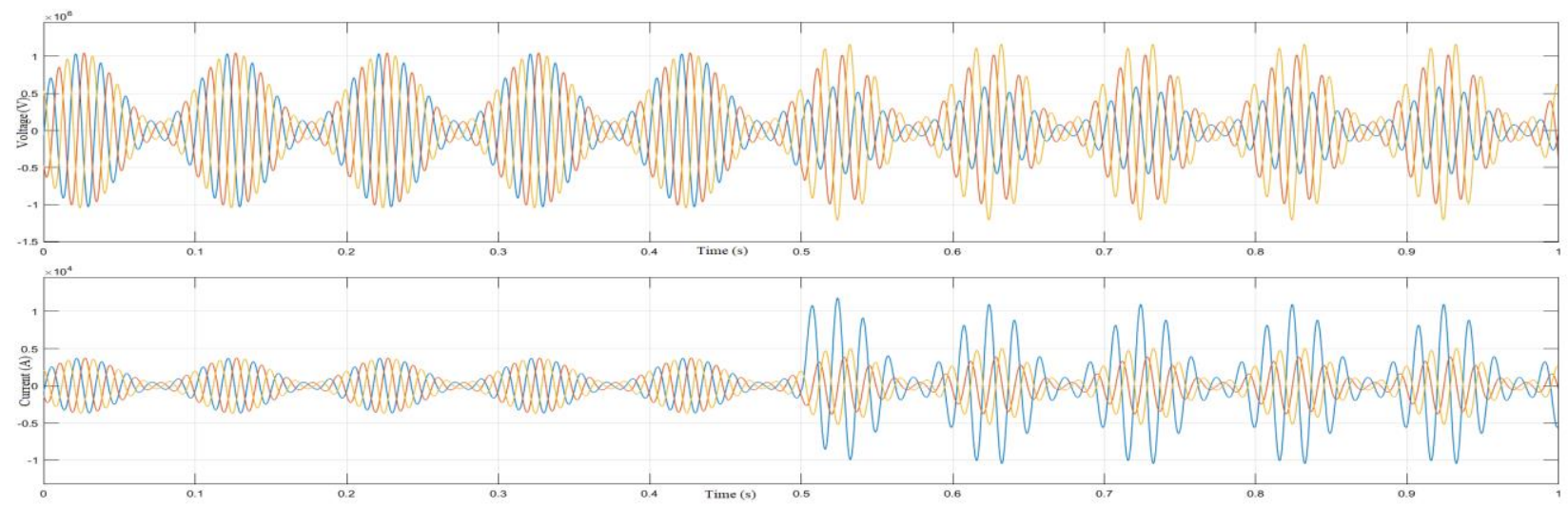

Fig. 2. Voltages and currents during power swing and LG fault. 
Fig. 3 and Fig. 5 indicate the locus of impedances in three dimensional space with respect to time. Fig. 3 shows that power swing creates a bi-conical plot with operating impedance between the cones. Fig. 4 shows that fault caused permanent shift in the operating impedance. Fig. 5 shows that first differential of $Z$ lead to conversion of bi-conical plot to single hyperboloid plot which expands and contracts with respect to swinging frequency resembling a hyperboloid. For better visualization of normal operation and power swing in three dimensional space, refer the appendix. Fig. 6 shows the variation in amplitudes for $\theta$ and $\mathrm{d} \theta / \mathrm{dt}$ before and after fault in the presence of power swing.

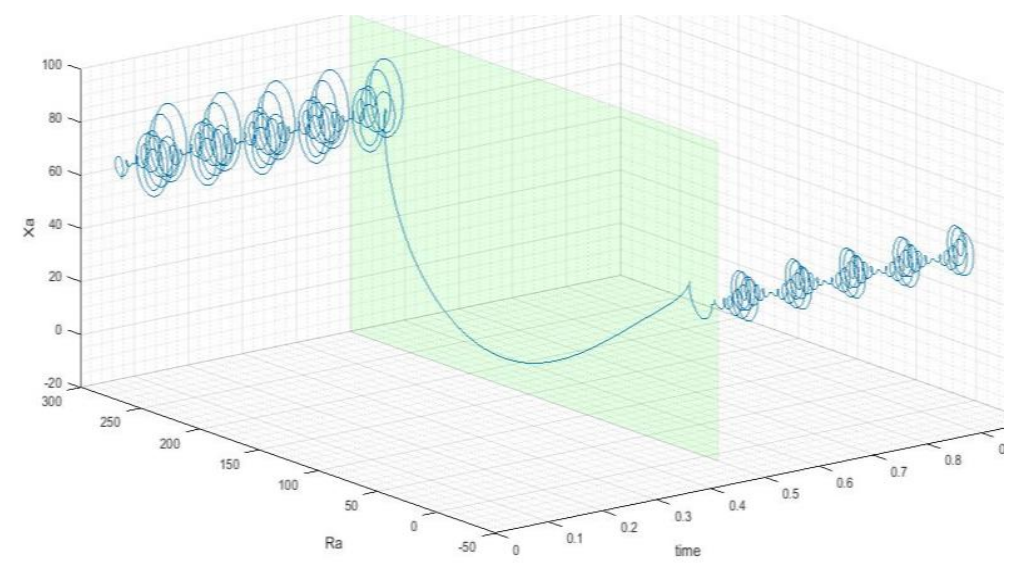

Fig. 3. R-X-t plot during power swing and LG fault.

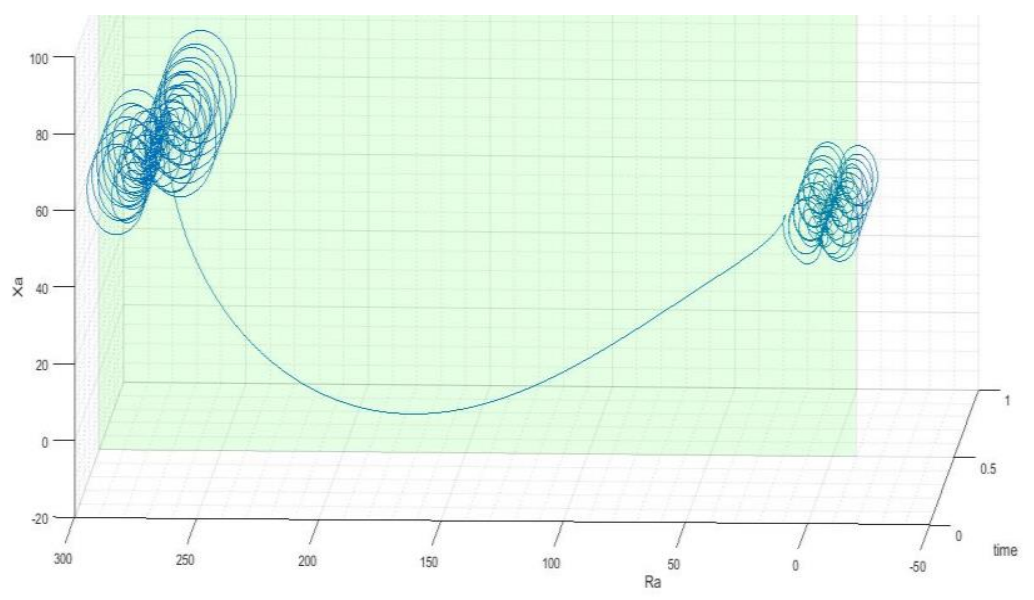

Fig. 4. R-X plot during power swing and LG fault.

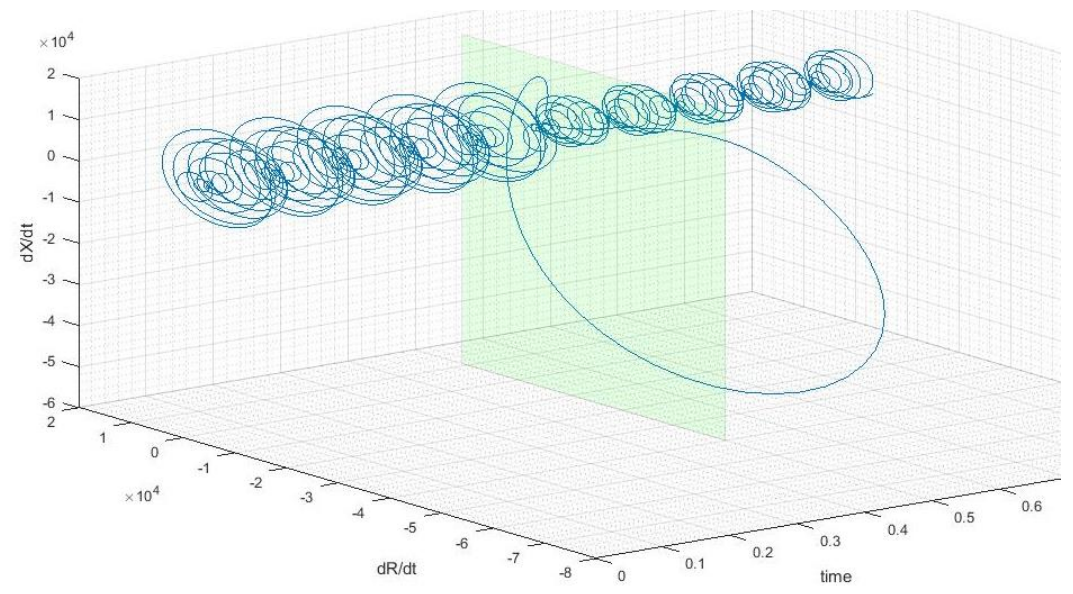

Fig. 5. dR/dt-dX/dt-t during swing and LG fault. 

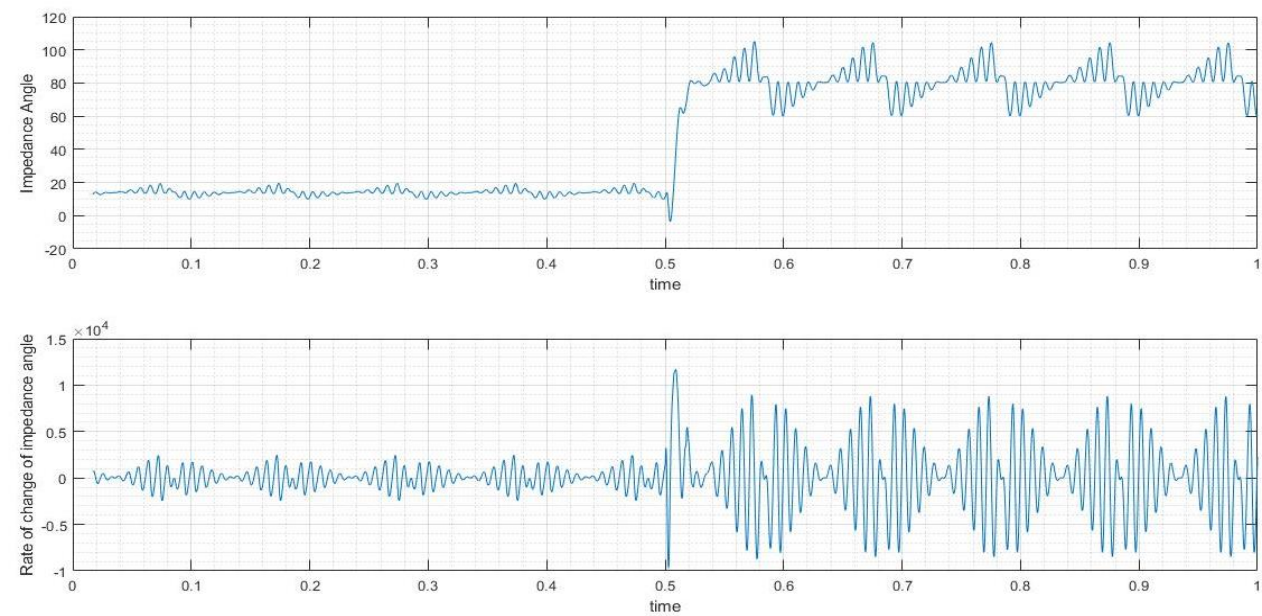

Fig. 6. $\theta$ and $\mathrm{d} \theta / \mathrm{dt}$ during swing and LG fault.

Fig. 7 indicates the delay in trip signal observed by the relay during the course of simulation. $\mathrm{d} \theta / \mathrm{dt}$ detected the fault in $1.8 \mathrm{~ms}$ after the application of fault.

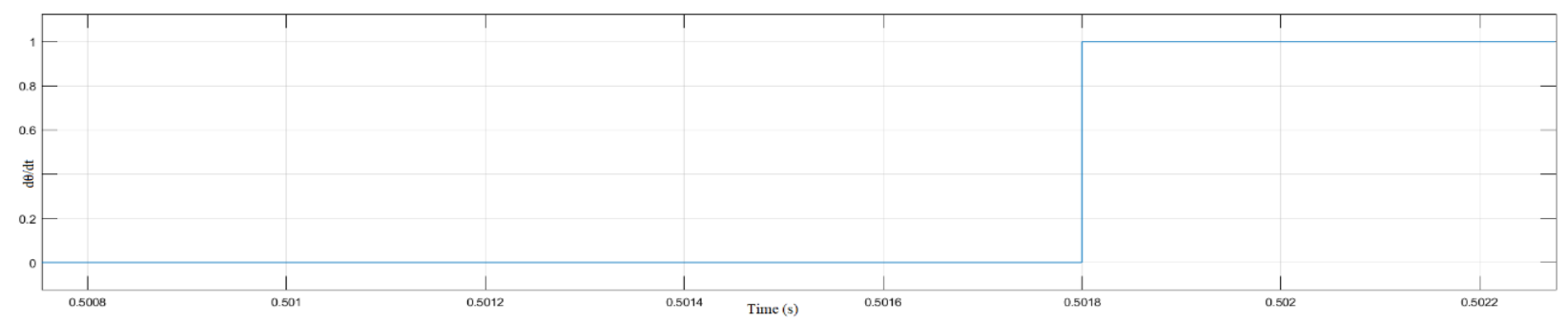

Fig. 7. Delay observed by $d \theta / d t$ after the application of LG fault.

\subsubsection{Line to line fault}

Line to Line (LL) fault was given at the load end of transmission line from $0.5 \mathrm{~s}$ to $1 \mathrm{~s}$. The voltages and currents are shown in the Fig. 8.
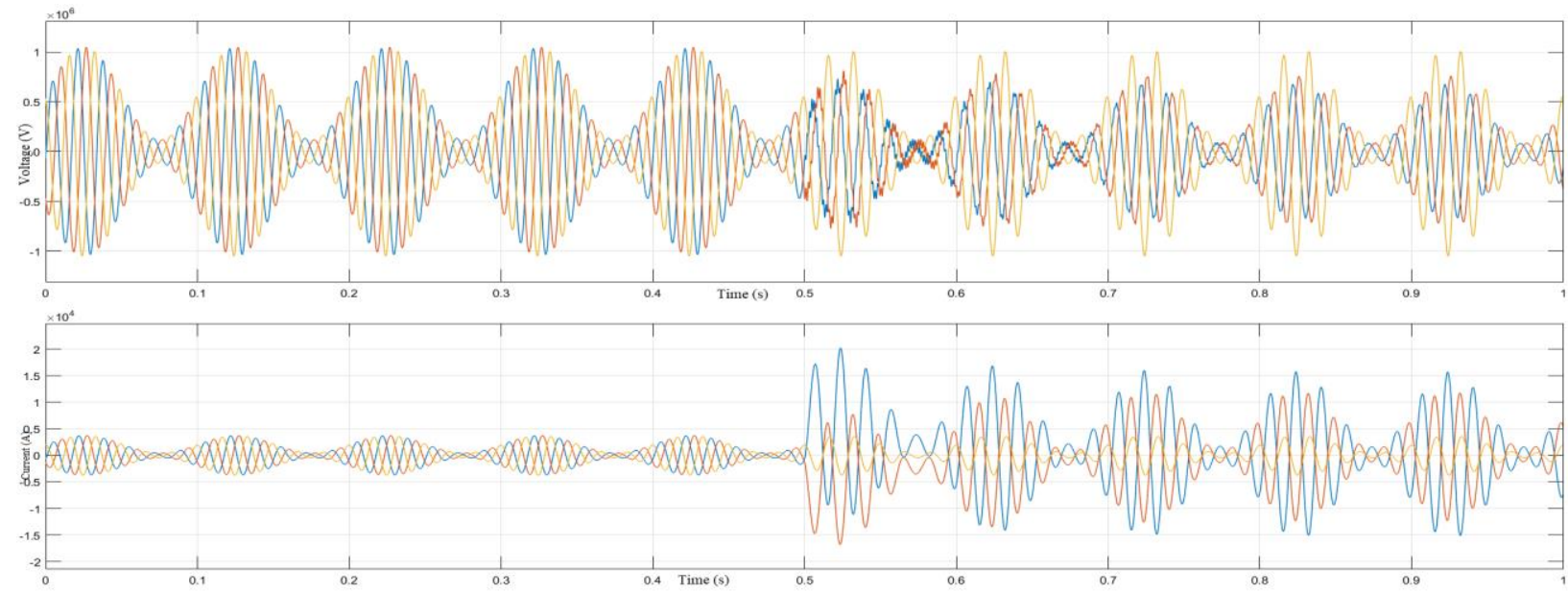

Fig. 8. Voltages and Currents during power swing and LL fault.

Fig. 9 and Fig. 10 indicate the locus of impedances in three dimensional space with respect to time. Fig. 11 shows the variation in amplitudes for $\theta$ and $d \theta / d t$ before and after fault in the presence of power swing. 
Comparing Fig. 9 and Fig. 11, it is clear that the DC shift in $\theta$ after fault as seen in Fig. 11 was responsible for the change in operating impedance as seen in Fig. 9. Differential angle had no DC value, and thus operating point remained the same before and after fault in Fig. 10 and Fig. 11.

Fig. 12 indicates the trip signal observed by the relay during the course of the simulation for line to line fault during power swing. $\mathrm{d} \theta / \mathrm{dt}$ detected the fault in $0.7 \mathrm{~ms}$ after the application of fault.

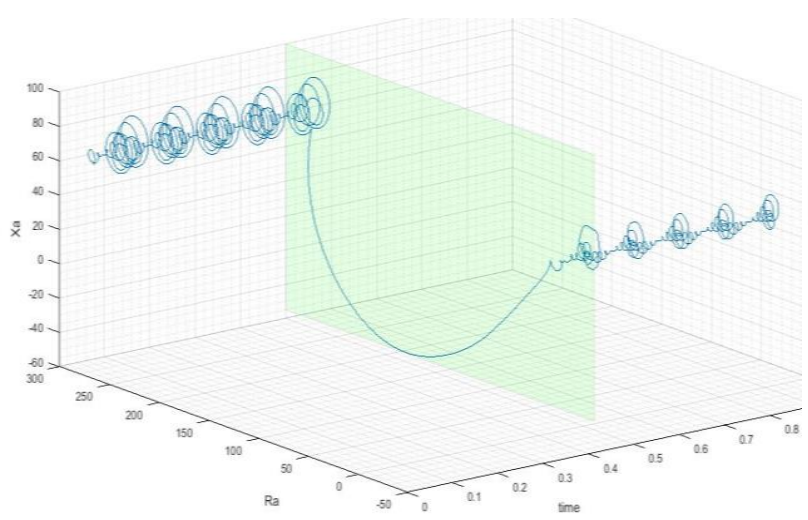

Fig. 9. R-X-t plot during power swing and LL fault.

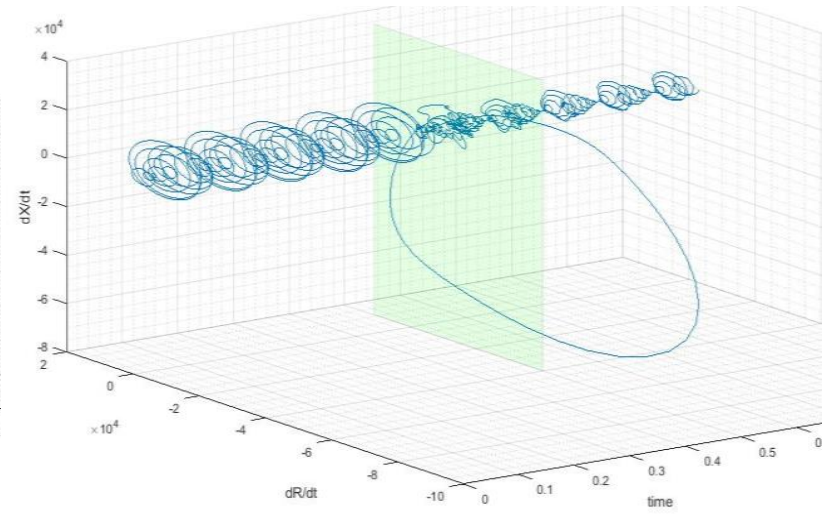

Fig. 10. dR/dt-dX/dt-t during swing and LL fault.
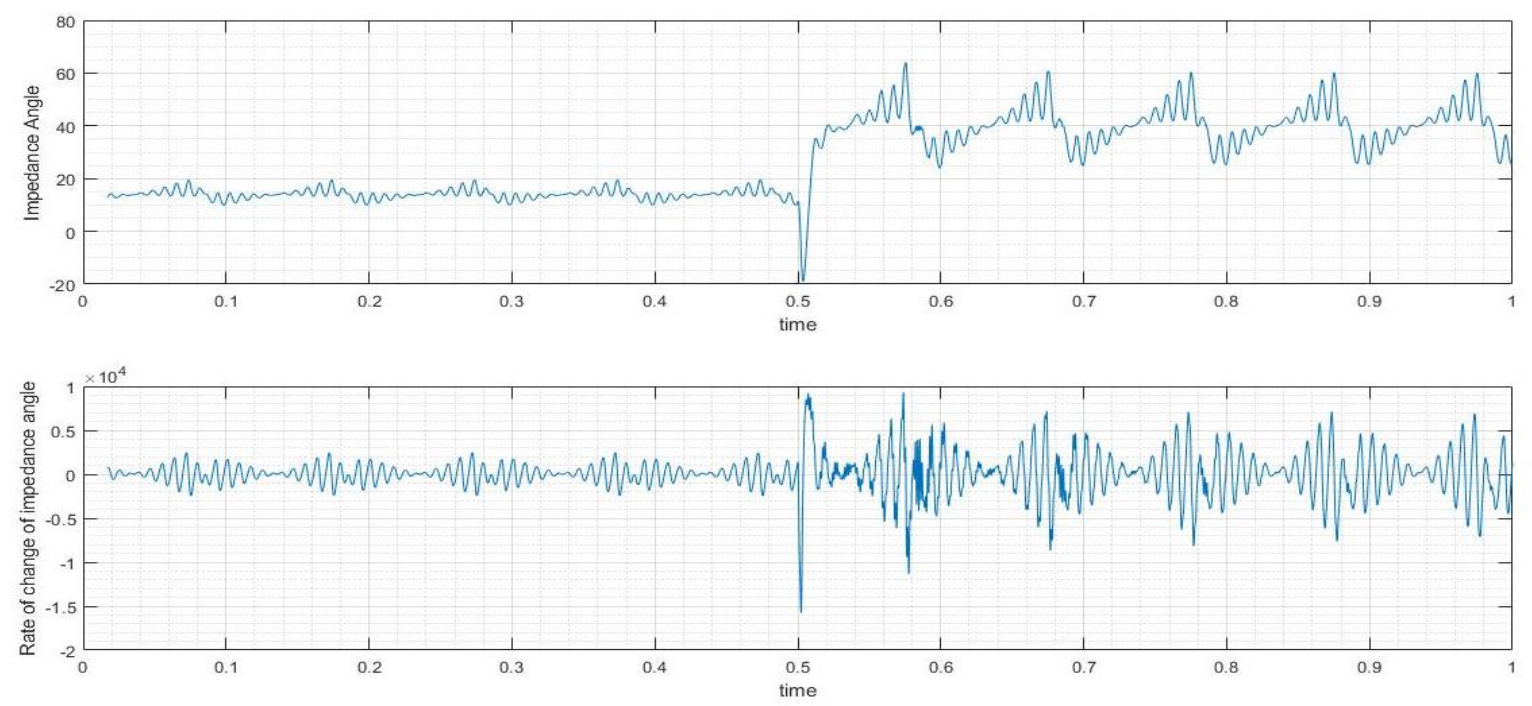

Fig. 11. $\theta$ and $\mathrm{d} \theta / \mathrm{dt}$ during power swing and LL fault.

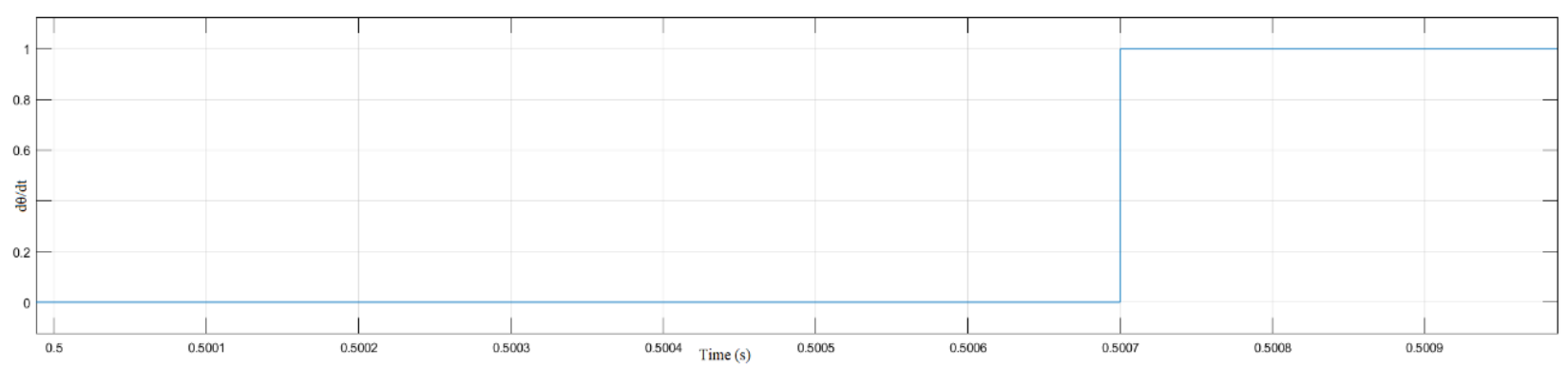

Fig. 12. Delay observed by $d \theta / d t$ after the application of LL fault.

\subsubsection{Open Line Fault}

Open line (OL) fault was given at the load end of transmission line from $0.5 \mathrm{~s}$ to $1 \mathrm{~s}$. The voltages and currents are shown in the Fig. 13. 

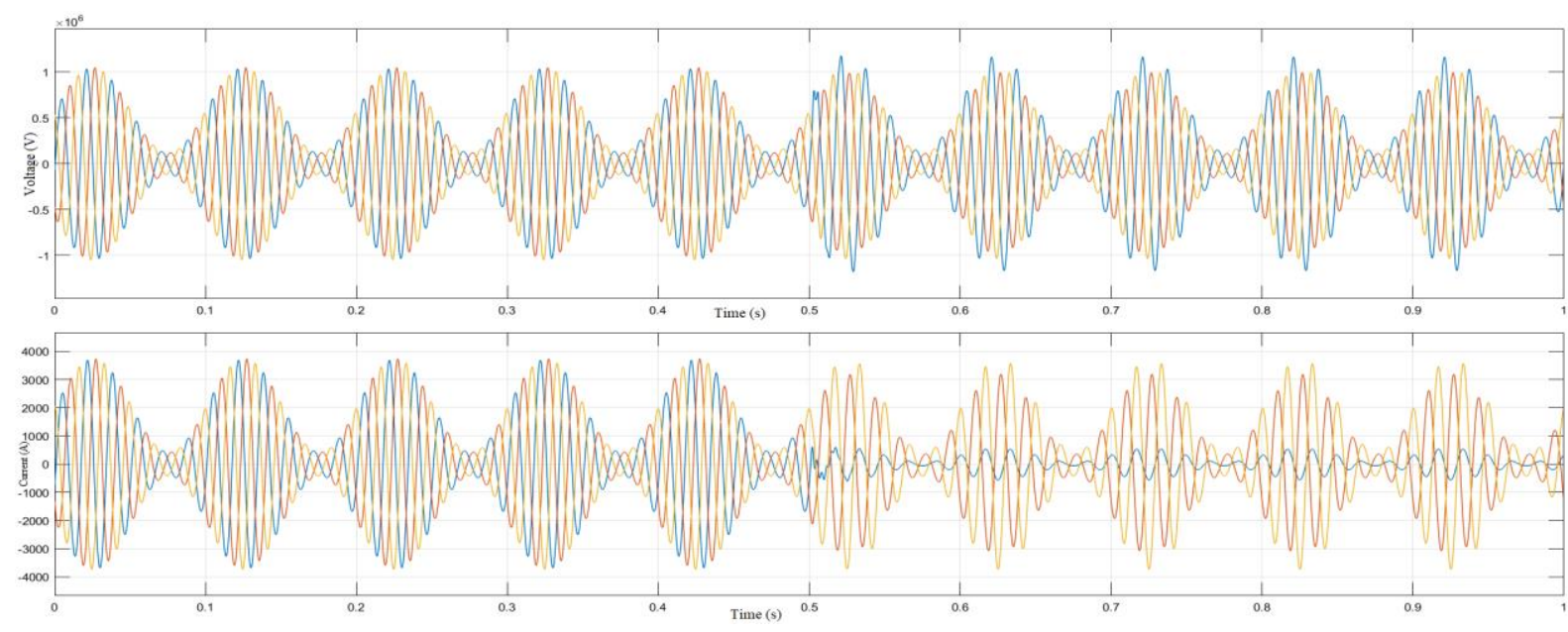

Fig. 13. Voltages and currents during power swing and OL fault.
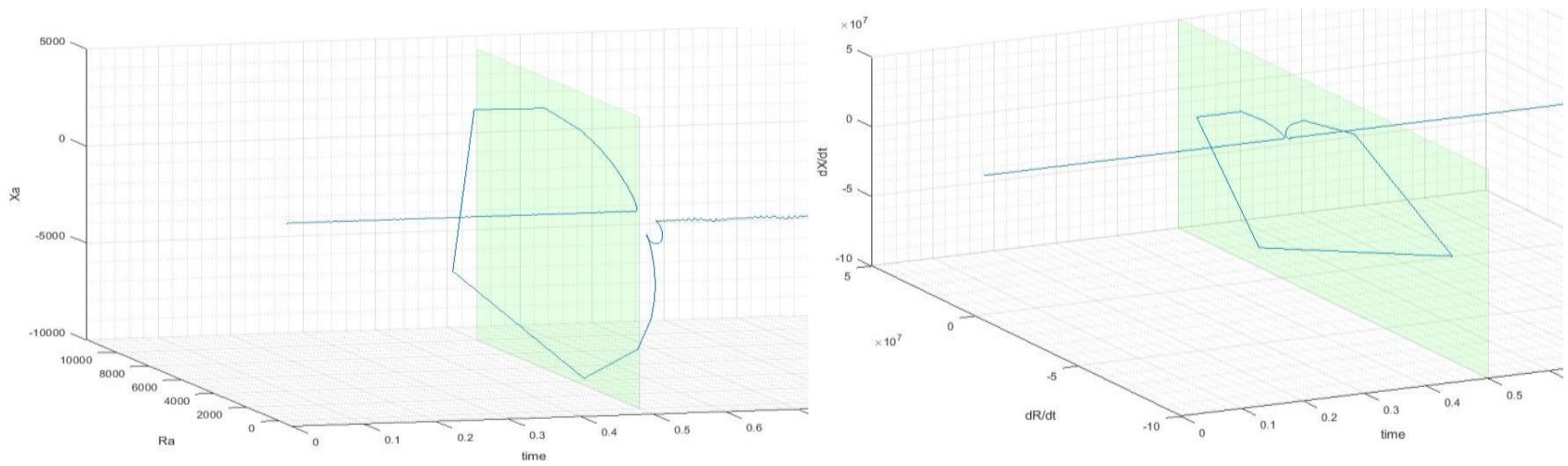

Fig. 14. R-X-t plot during swing and OL fault.

Fig. 15. dR/dt-dX/dt-t during swing and OL fault.

Fig. 14 and Fig. 15 indicate the locus of impedances in three dimensional space with respect to time. Fig. 16 shows the variation in amplitudes for $\theta$ and $d \theta / d t$ before and after fault in the presence of power swing. Due to open line fault (OL), the impedances rose exponentially. The impedances observed were caused by travelling lines in a conductor with open end. The transmission line possesses rated system voltage with charging currents passing through it. Since charging currents are very small, the ratio of Voltage and Current yielded a very high capacitive impedance as evident from the Fig. 14 and Fig. 16.

Fig. 17 indicates the trip signal observed by the relay during the course of the simulation for open line fault (OL) during power swing. $\mathrm{d} \theta / \mathrm{dt}$ detected the fault in $2.1 \mathrm{~ms}$ after application of the fault.
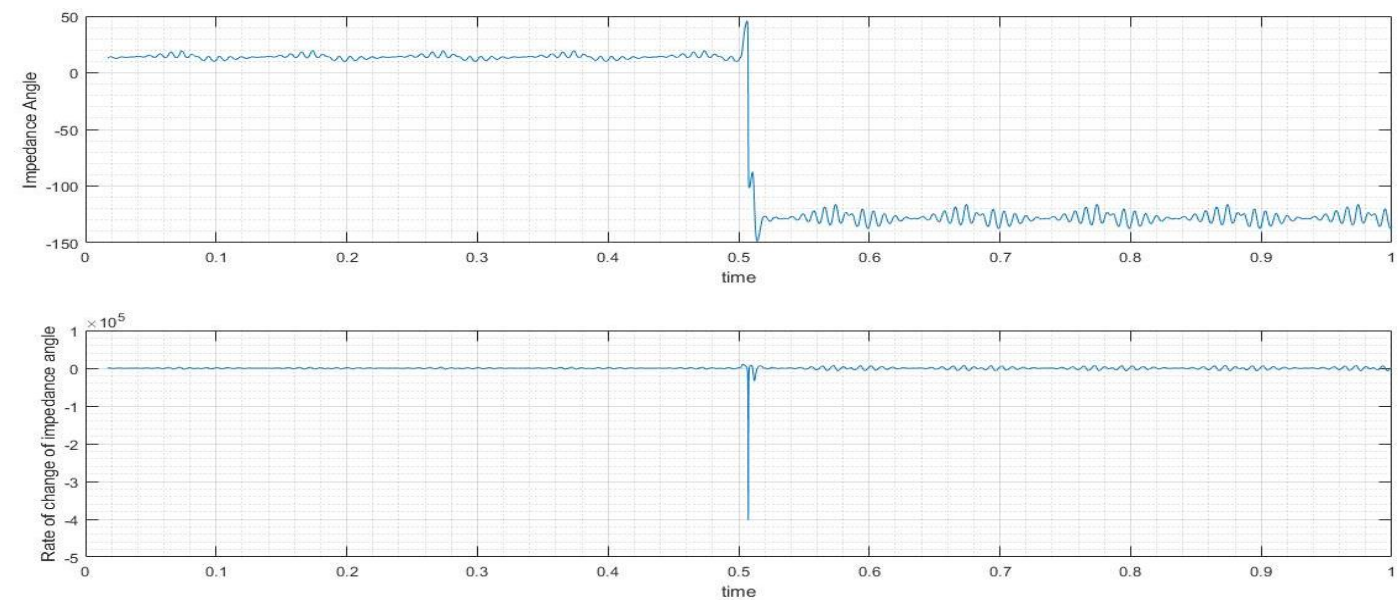

Fig. 16. $\theta$ and $d \theta / d t$ during power swing and OL fault. 


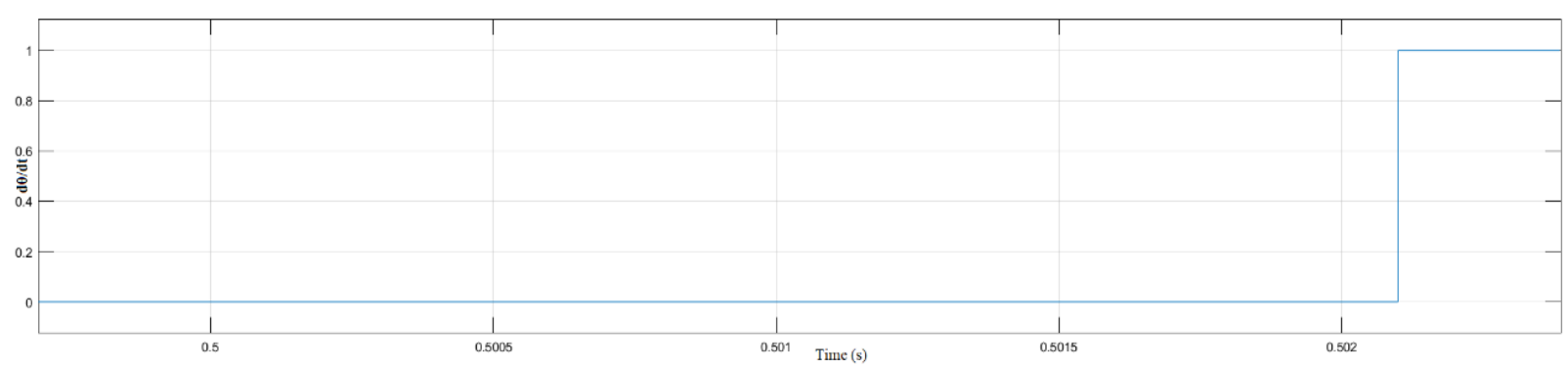

Fig. 17. Delay observed by $\mathrm{d} \theta / \mathrm{dt}$ after the application of OL fault.

\subsubsection{High Impedance Fault}

An impedance of $200 \mathrm{ohms}$ was inserted between line and ground to simulate the high impedance (HI) line to ground fault from $0.5 \mathrm{~s}$ to $1 \mathrm{~s}$. The voltages and currents are shown in the Fig. 18.
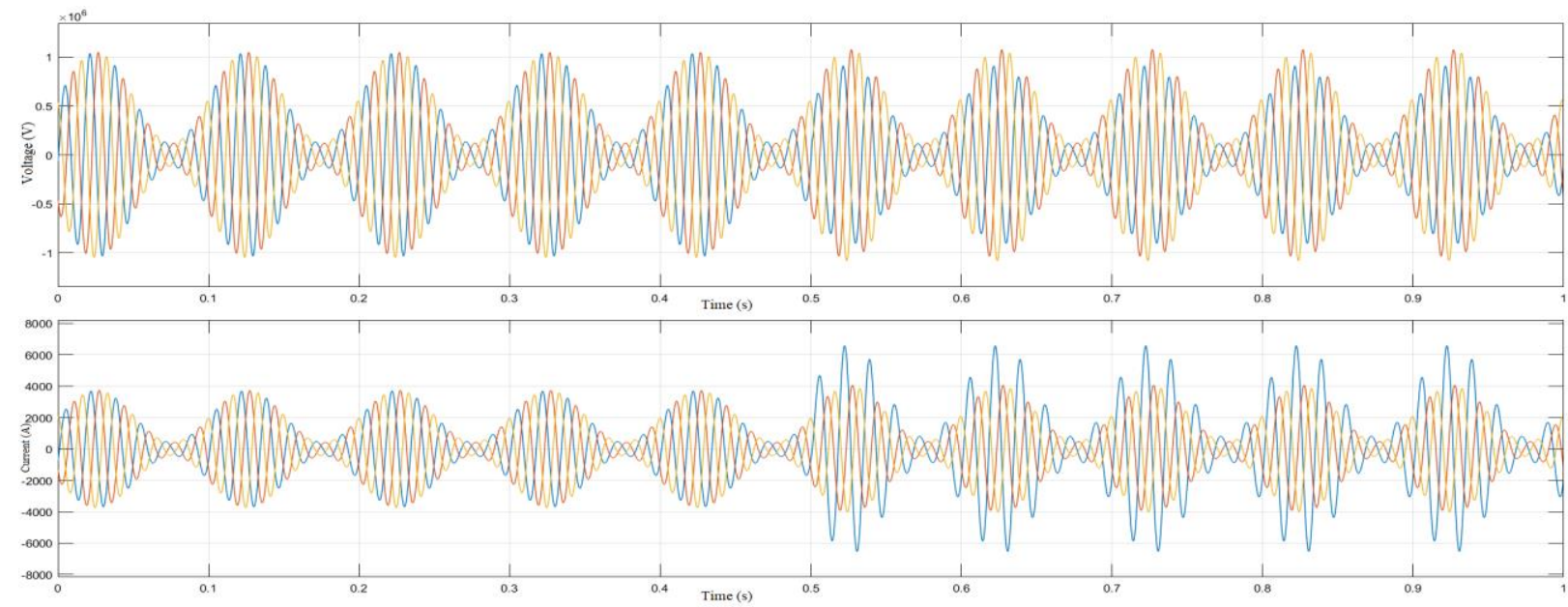

Fig. 18. Voltages and Currents during power swing and HI fault.

Fig. 19 and Fig. 20 indicate the locus of impedances in three dimensional space with respect to time. Fig. 21 shows the variation in amplitudes for $\theta$ and $d \theta / d t$ before and after high impedance fault in the presence of power swing with respect to time. The plots resembled a line to ground fault, but the fault was greatly magnified in differential impedance.

Fig. 22 indicates the trip signal observed by the relay during the course of the simulation for high impedance ground fault during power swing. $d \theta / d t$ detected the high impedance fault in $2.35 \mathrm{~ms}$ after the application of fault.

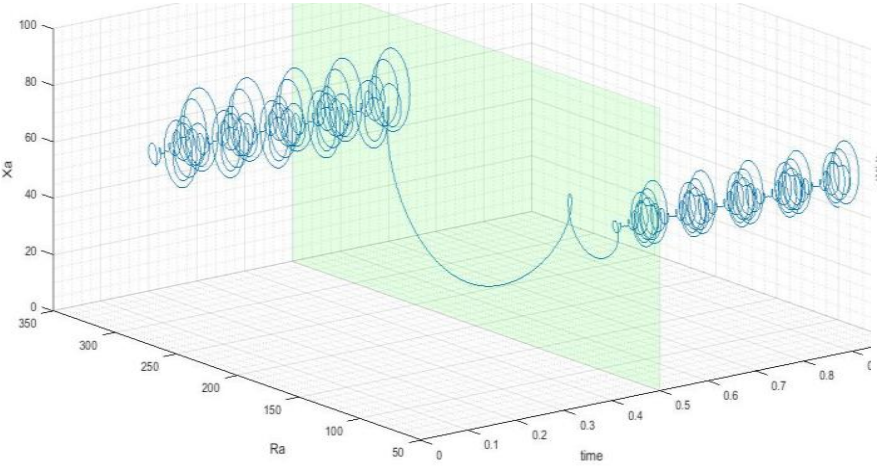

Fig. 19. R-X-t plot during swing and HI fault.

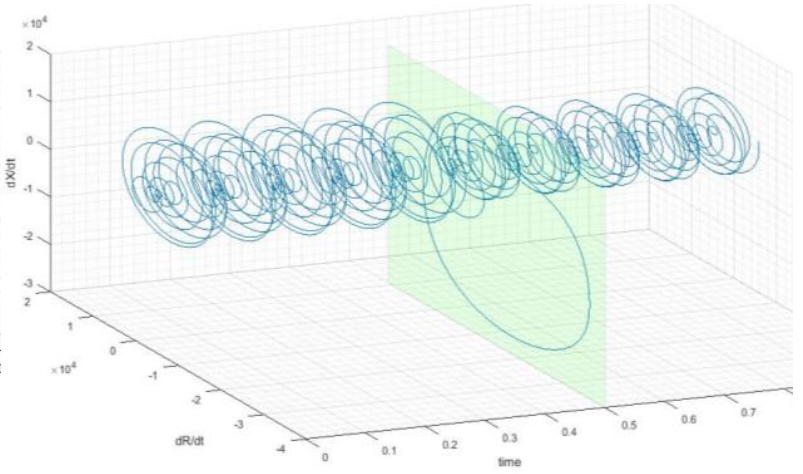

Fig. 20. dR/dt-dX/dt-t during swing and HI fault. 

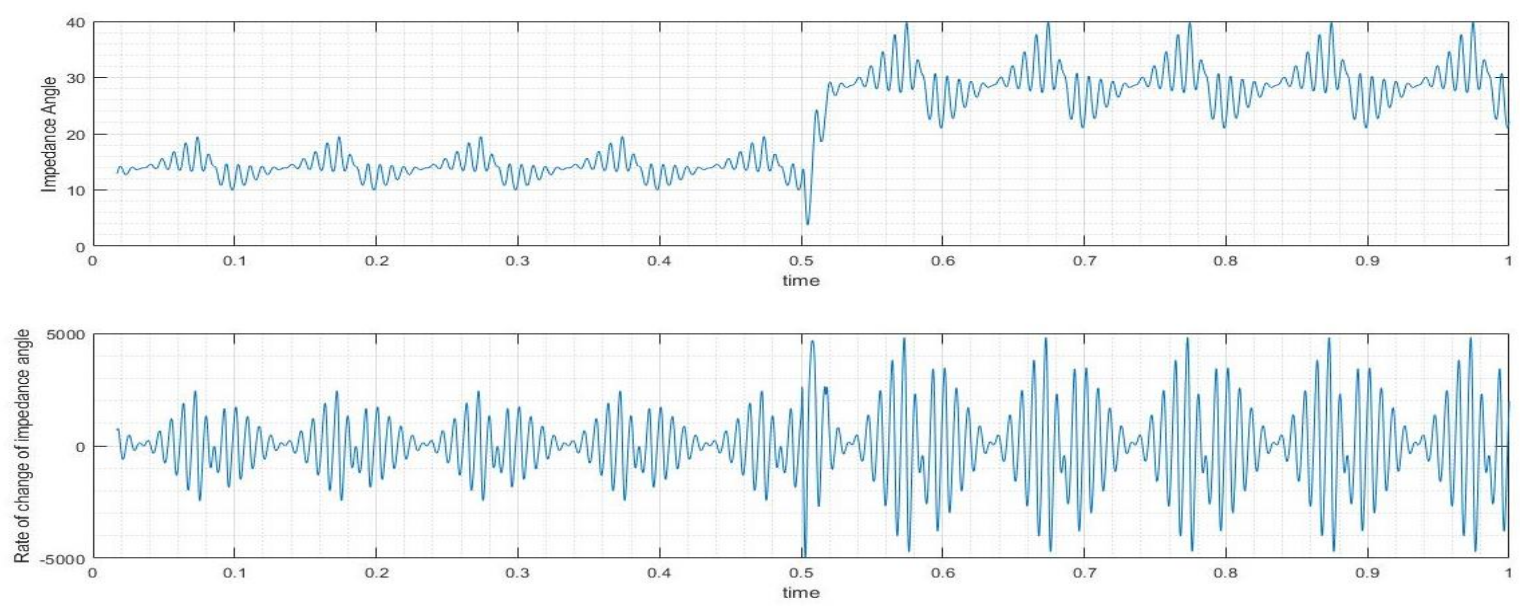

Fig. 21. $\theta$ and $\mathrm{d} \theta / \mathrm{dt}$ during power swing and HI fault.

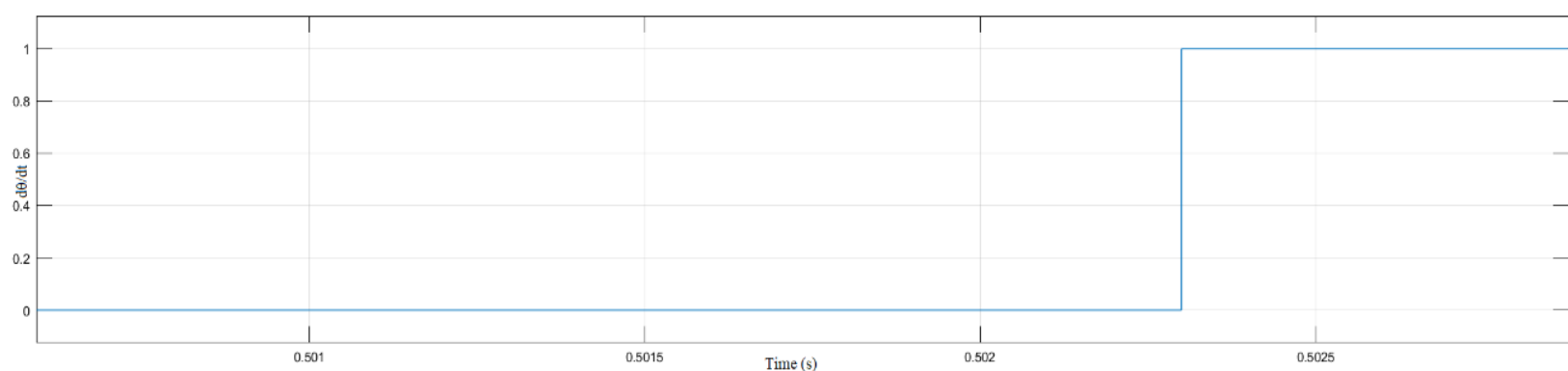

Fig. 22. Delay observed by $\mathrm{d} \theta / \mathrm{dt}$ after the application of $\mathrm{HI}$ fault.

\subsection{Unstable Swing}

Unstable swing was simulated to test the efficiency of impedance angles in differentiating unstable power swing from a stable power swing. The green colored transparent plane observed in three dimensional plots indicates the instant when the stable swing becomes unstable (at $0.5 \mathrm{~s}$ ). The voltages and currents are shown in the Fig. 23.

Stable swing can be differentiated from unstable swing based on the maximum and minimum points in voltages. The minimum voltage after the application of unstable swing can be seen to reach $0 \mathrm{~V}$ at regular intervals indicating pole slipping in generators.

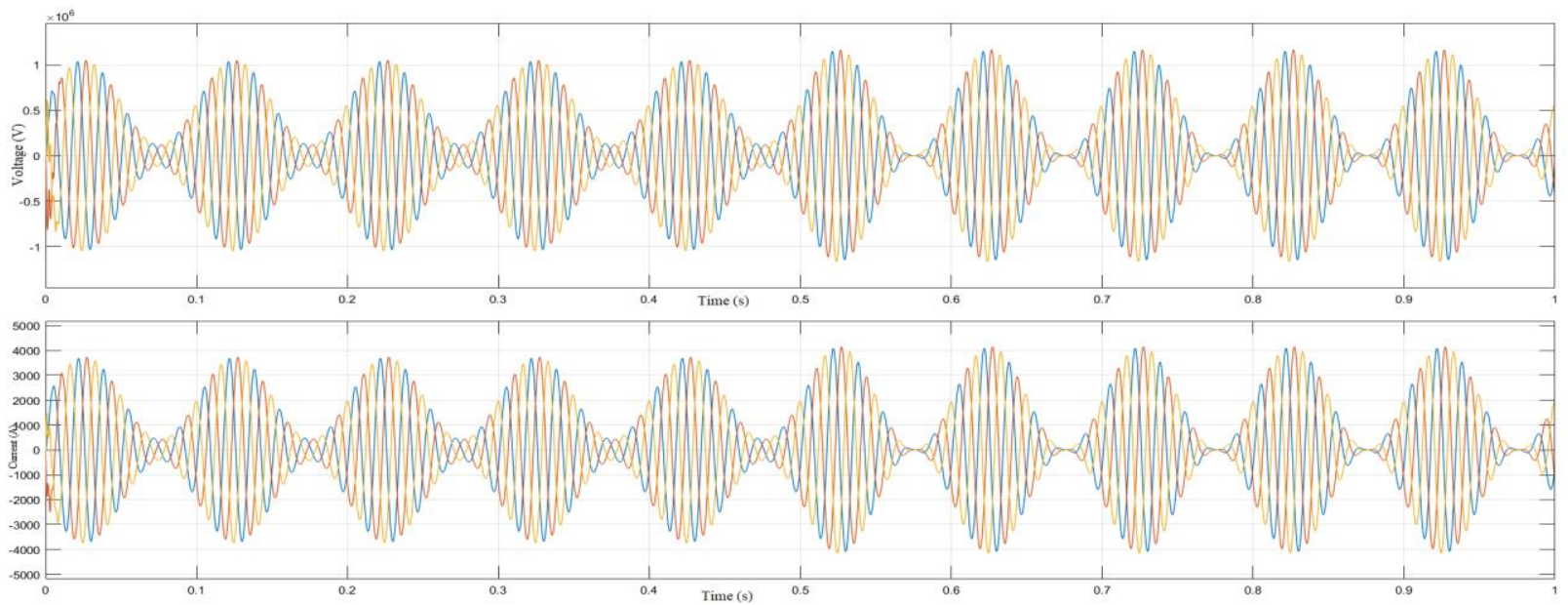

Fig. 23. Voltages and Currents during stable and unstable power swing. 


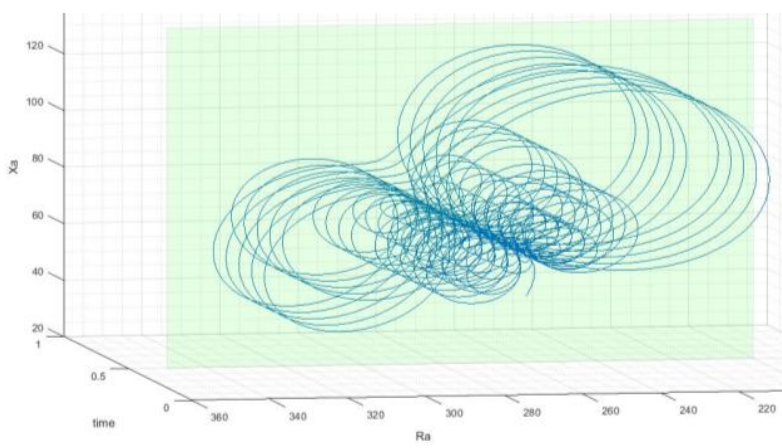

Fig. 24. R-X-t during stable and unstable swing.

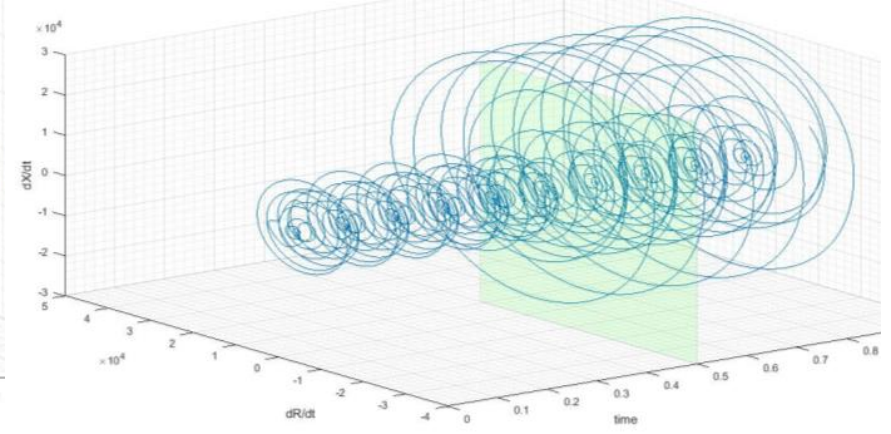

Fig. 25. $d R / d t-d X / d-t$ for stable and unstable swing.
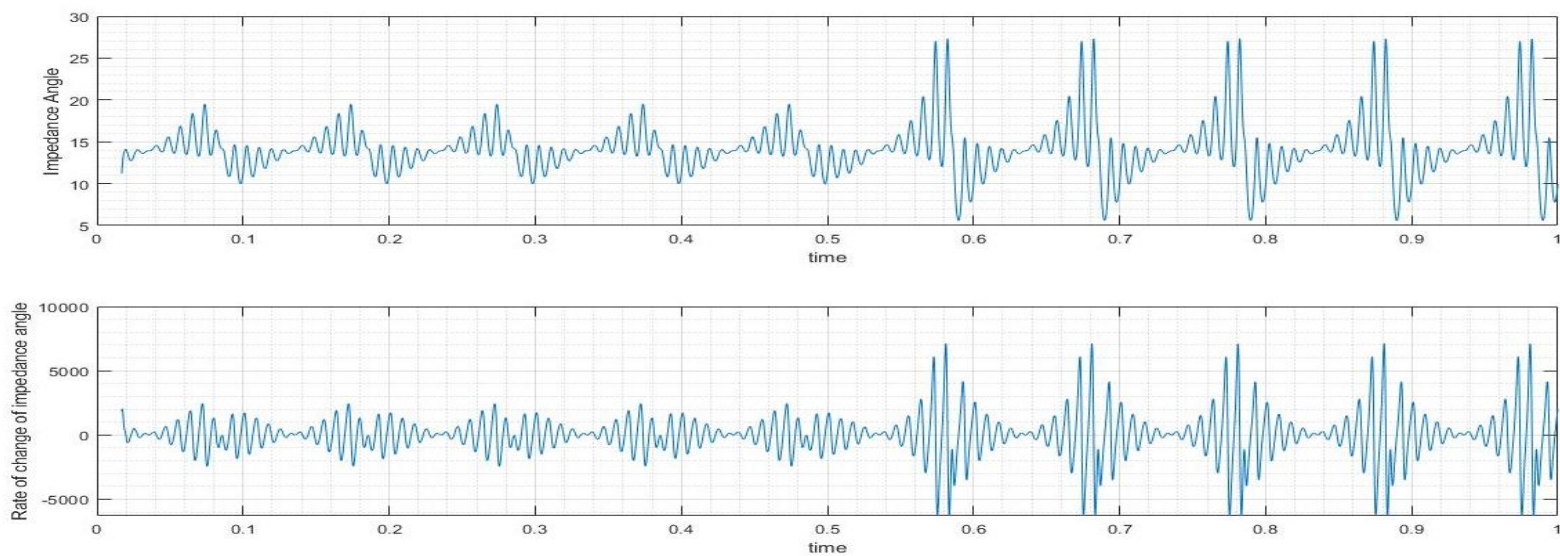

Fig. 26. $\theta$ and $d \theta / d t$ during stable and unstable power swing.

Fig. 24 and Fig. 25 indicate the locus of impedances in three dimensional space with respect to time. Fig. 24 shows that power swing creates a bi-conical plot for both stable and unstable swing. Both stable and unstable swing didn't create a permanent shift in the operating impedance. Fig. 25 shows that first differential of $\mathrm{Z}$ lead to conversion of bi-conical plot to single plot which expands and contracts with respect to swinging frequency resembling a hyperboloid. Fig. 26 shows the variation in amplitudes for $\theta$ and $d \theta / d t$ for both stable and unstable power swings.

Fig. 27 indicates the trip signal observed by the relay during the course of the simulation. $d \theta / d t$ detected the unstable swing in $71.7 \mathrm{~ms}$ after the system became unstable.

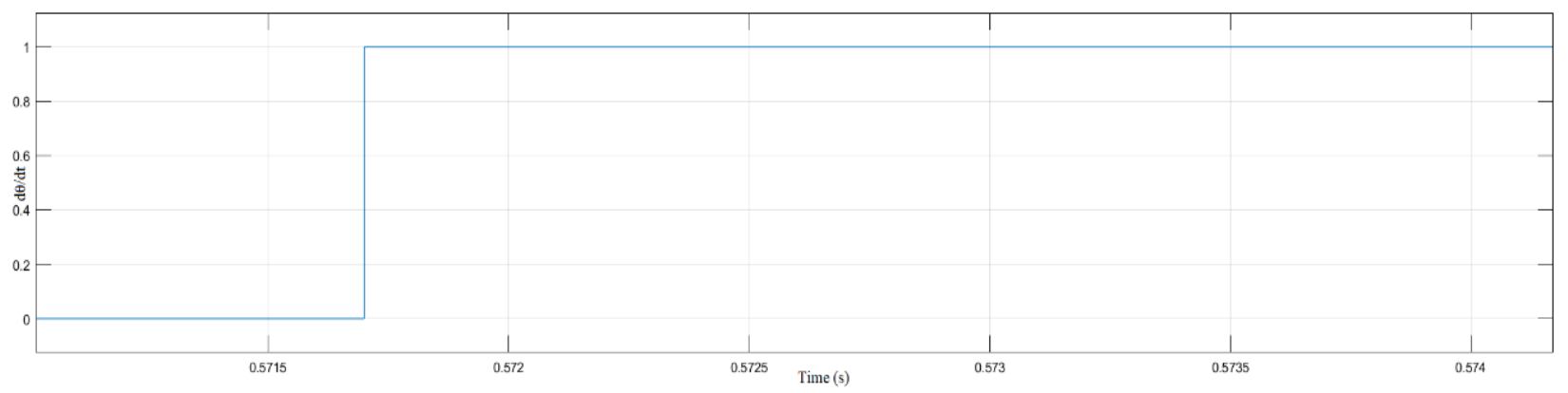

Fig. 27. Delay observed by $\mathrm{d} \theta / \mathrm{dt}$ after the application of unstable swing.

\section{Conclusion}

An ideal impedance waveform without any disturbance will be helical in both R-X-t space and dR/dt $\mathrm{dX} / \mathrm{dt}$ - t. Power swing cause bi-conical loops in R-X-t plane causing variation in Z. Differential impedances 
caused hyperboloid plots in $\mathrm{dR} / \mathrm{dt}-\mathrm{dX} / \mathrm{dt}-\mathrm{t}$ space. The plots for $\mathrm{Z}$ during normal and power swing situations are displayed in Appendix A and Appendix B respectively.

The transparent planes indicated how the locus of impedance varied when a disturbance occurred. Faults caused permanent shift in operating impedances. Short circuit faults were inductive due to positive impedance angles and open circuit faults were capacitive due to negative impedance angles. Unstable swing caused significant change in amplitude of swings. The summary of obtained results is shown in Table 1.

Table 1. Summary of Observations

\begin{tabular}{cccccc}
\hline \hline Disturbance & Time $(\mathrm{ms})$ & $\mathrm{d} \theta / \mathrm{dt}(\mathrm{ms})$ & Delay $(\mathrm{ms})$ & $\theta$ shift & Nature of the shift \\
\hline LG Fault & 500 & 501.8 & 1.8 & $60^{\circ}$ & Inductive \\
\hline LL Fault & 500 & 500.7 & 0.7 & $30^{\circ}$ & Inductive \\
\hline OL Fault & 500 & 502.1 & 2.1 & $-120^{\circ}$ & Capacitive \\
\hline HI Fault & 500 & 502.35 & 2.35 & $15^{\circ}$ & Inductive \\
\hline Unstable Swing & 500 & 571.7 & 71.7 & $0^{\circ}$ & No Shift \\
\hline \hline
\end{tabular}

LG fault caused a net phase shift of $60^{\circ}$ in impedance angle (Fig. 6). Fault caused permanent shift in operating impedance (Fig. 3 ) and took $1.8 \mathrm{~ms}$ to be detected by $\mathrm{d} \theta / \mathrm{dt}$ (Fig. 7 ).

LL fault caused a net phase shift of $30^{\circ}$ in impedance angle (Fig. 11). Fault caused permanent shift in operating impedance (Fig. 9) and took $0.7 \mathrm{~ms}$ to be detected by d $\theta /$ dt (Fig. 12).

Open line fault caused a net phase shift of $-120^{\circ}$ in impedance angle (Fig. 16). Fault caused denergising of the circuit leading to presence of charging currents resulting in very high impedance shift (Fig. 14) and took $2.1 \mathrm{~ms}$ to be detected by $\mathrm{d} \theta / \mathrm{dt}$ (Fig. 17).

High impedance faults caused a net phase shift of $15^{\circ}$ in impedance angle (Fig. 21). Fault caused permanent shift in operating impedance and resembled LG fault to great extent with respect to dynamics in R-X-t and dR/dt - dX/dt - t plots (Fig. 19). $d \theta / d t$ took 2.35ms to detect the fault (Fig. 22).

Injecting an unstable power swing didn't change the operating angle, rather led to increase in the magnitude of oscillations (Fig. 24 and Fig. 26). The differential impedance angle took $71.7 \mathrm{~ms}$ to detect the unstable swing (Fig. 27).

Unstable swing accompanied with out-of-step is the leading cause of blackout around the globe. A stable swing creates ripples throughout the network which will be attenuated as the power swing traverses through the network. The ripples from unstable swing gets magnified as the power swing traverses through the network causing peak voltages of 0 pu and 2 pu (as seen in Fig. 23 after $0.5 \mathrm{~s}$ ) accompanied by slipping of poles in generator. They lead to both voltage instability and frequency instability. Thus, unstable swing must be avoided in order to maintain the grid stability. Studies will be carried out in future in order to quickly differentiate an unstable swing from stable swings by mathematically modeling a power swing and identifying key frequencies and amplitudes responsible for the swing.

\section{Future Work}

Power swing in a system combines both stability and fault studies. Since distance relays operate using resistance and reactance as the input, it is important to convert some of the known parameters in the circuit to impedances. Relays obtain information of the power system based on time varying voltages and currents. Thus, the generic transformation for studying low frequency oscillations from $0.1 \mathrm{~Hz}$ to $10 \mathrm{~Hz}$ will be transforming voltages and currents with the swing in them into impedances. This impedance (both magnitude and angle) will be used for analyzing fault and understanding stability of the system in view of both stable and unstable swings.

The major reason for focusing on impedance angle as the parameter to differentiate faults from power swing is due to its independence to number of parallel circuits, length of transmission lines and overloading 
capability (X/R ratio remains fairly constant in transmission system except during faults).

\section{Appendix A}

Plots during normal conditions devoid of faults for a system operating at $735 \mathrm{kV}, 60 \mathrm{~Hz}$ are shown below.

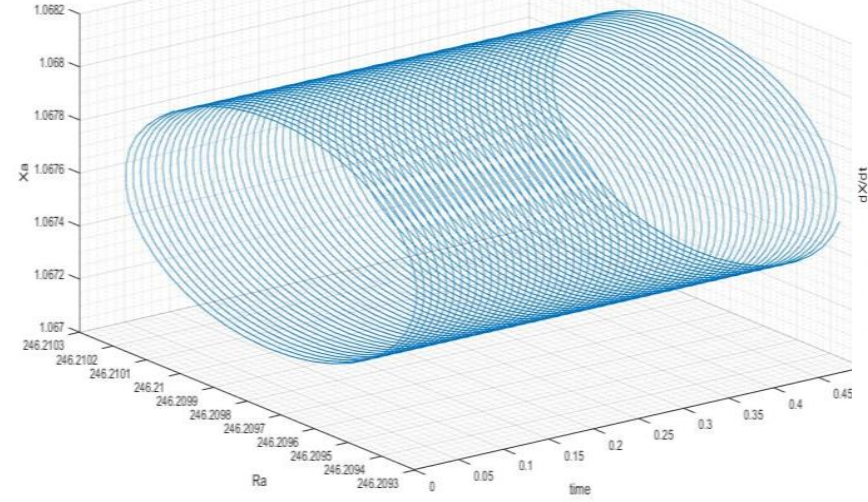

Fig. 28. $\mathrm{R}-\mathrm{X}-\mathrm{t}$ plot without any disturbance.

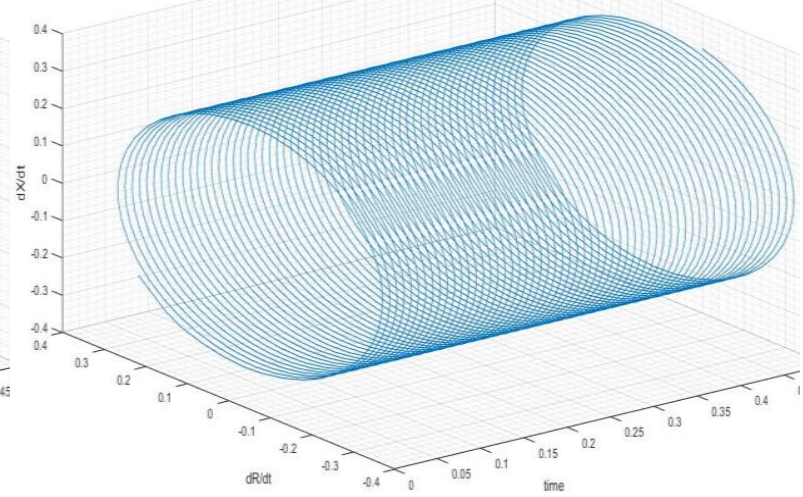

Fig. 29. dR/dt-dX/dt-t without any disturbance.

From Fig. 28,

$\mathrm{R}$ was oscillating between 246.2094 and $246.2102 . \Delta \mathrm{R}=0.8 \mathrm{~m} \Omega, \mathrm{R}_{\text {mean }}=246.2098 \Omega$

$\mathrm{X}$ was oscillating between 1.0672 and 1.068. $\Delta \mathrm{X}=0.8 \mathrm{~m} \Omega, \mathrm{X}_{\text {mean }}=1.0676 \Omega$

$\Delta \mathrm{R}$ and $\Delta \mathrm{X}$ have equal values leading to circle. $\mathrm{R}_{\text {mean }}$ and $\mathrm{X}_{\text {mean }}$ are the system average values.

$\mathrm{R}$ and $\mathrm{X}$ are almost constant value due to negligible variations in $\mathrm{R}$ and $\mathrm{X}(\Delta \mathrm{R}$ and $\Delta \mathrm{X}$ are in $\mathrm{m} \Omega$ ), thus uniform oscillation of impedances.

From Fig. 29,

$\mathrm{dR} / \mathrm{dt}$ was oscillating between -0.3 and $0.3 . \Delta \mathrm{dR} / \mathrm{dt}=0.6 \Omega / \mathrm{s} ; \mathrm{dR} / \mathrm{dt}_{\text {mean }}=0$

$\mathrm{dX} / \mathrm{dt}$ was oscillating between -0.3 and $0.3 . \Delta \mathrm{dX} / \mathrm{dt}=0.6 \Omega / \mathrm{s} . \mathrm{dX} / \mathrm{dt}_{\text {mean }}=0$

$\Delta \mathrm{dR} / \mathrm{dt}$ and $\Delta \mathrm{dX} / \mathrm{dt}$ have equal values leading to circle. $\mathrm{dR} / \mathrm{dt}_{\text {mean }}$ and $\mathrm{dX} / \mathrm{dt}_{\text {mean }}$ are equal to zero due to absence of variation in system average values. $d R / d t$ and $d X / d t$ are small due to negligible variations in system.

\section{Appendix B}

Plots during a power swing devoid of faults for a system operating at $735 \mathrm{kV}, 60 \mathrm{~Hz}$ possessing a swing frequency of $1 \mathrm{~Hz}$.

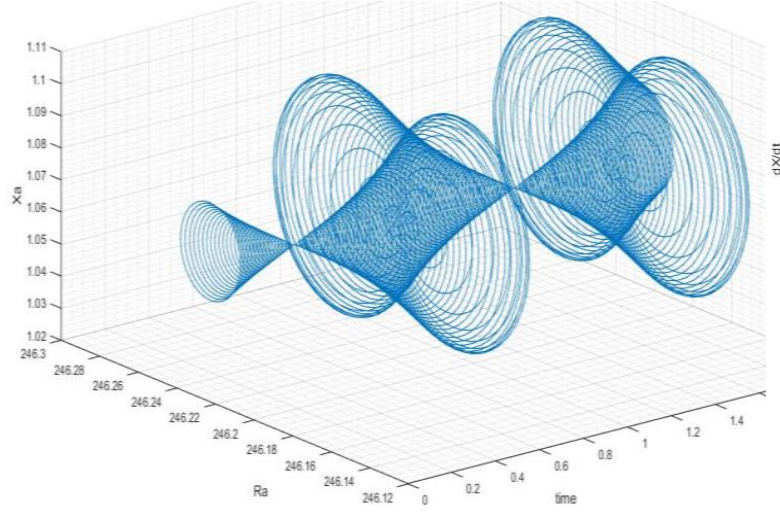

Fig. 30. $\mathrm{R}-\mathrm{X}-\mathrm{t}$ plot with power swing.

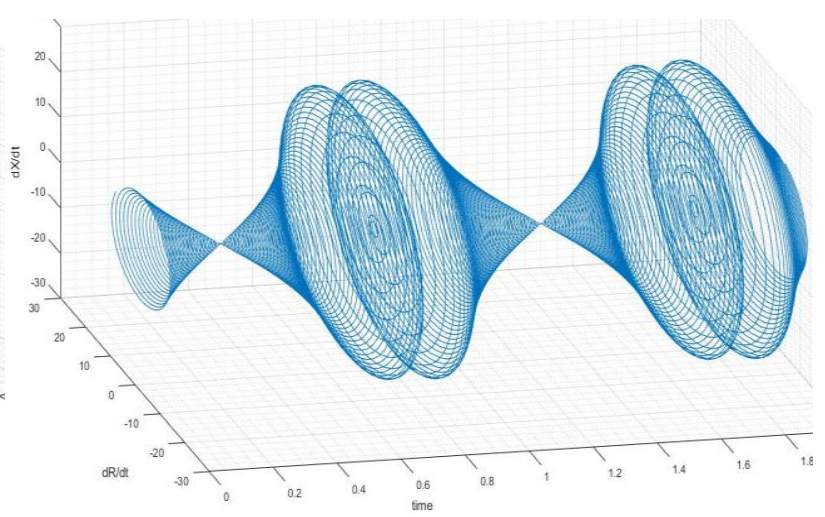

Fig. 31. $d R / d t-d X / d t-t$ plot with power swing. 
From Fig. 30,

$\mathrm{R}$ was oscillating between $246.14 \Omega$ and $246.28 \Omega$; X was oscillating between $1.1 \Omega$ and $1.03 \Omega$.

$\mathrm{R}_{\text {mean }}=246.21 \Omega$ (almost as without power swing); $\mathrm{X}_{\text {mean }}=1.065 \Omega$ (almost as without power swing)

$\Delta \mathrm{R}_{\max }$ (extremes of the two cones in R axis) $=140 \mathrm{~m} \Omega ; \Delta \mathrm{X}_{\max }$ (extremes of one cone in X axis) $=70 \mathrm{~m} \Omega$;

$\Delta \mathrm{R}_{\min }$ (apex of the cone in $\mathrm{R}$ axis) $=0 ; \Delta \mathrm{X}_{\min }$ (apex of the cone in $\mathrm{X}$ axis) $=0$.

Unlike normal conditions, presence of power swing introduced maximum and minimum values in impedances which vary as a function of time. Thus, presence of swinging frequency leads to variation of $\mathrm{R}$ and X leading to Bi-Conical plot.

From Fig. 31,

$\mathrm{dR} / \mathrm{dt}$ was oscillating between $-20 \Omega / \mathrm{s}$ and $20 \Omega / \mathrm{s}$. dX/dt was oscillating between $-20 \Omega / \mathrm{s}$ and $20 \Omega / \mathrm{s}$.

$\mathrm{dR} / \mathrm{dt}_{\text {mean }}=0 ; \mathrm{dX} / \mathrm{dt}_{\text {mean }}=0$

$\Delta \mathrm{dR}_{\max } / \mathrm{dt}$ (extreme ends in $\mathrm{dR} / \mathrm{dt}$ axis) $=40 \Omega / \mathrm{s} ; \Delta \mathrm{dX} \max / \mathrm{dt}$ (extreme ends in $\mathrm{dX} / \mathrm{dt}$ axis) $=40 \Omega / \mathrm{s}$;

$\Delta \mathrm{dR}_{\min } / \mathrm{dt}$ (apex of the hyperbola in $\mathrm{dR} / \mathrm{dt}$ axis) $=0 ; \Delta \mathrm{dX} \min / \mathrm{dt}$ (apex of the hyperbola in $\mathrm{dX} / \mathrm{dt}$ axis) $=0$;

Though $\Delta \mathrm{dR} / \mathrm{dt}$ and $\Delta \mathrm{dX} / \mathrm{dt}$ were always equal, but they converged and diverged with respect to time depending on the frequency of the power swing yielding a hyperboloid plot. This is evident by the presence of maximum and minimum values within the $\mathrm{dR} / \mathrm{dt}$ and $\mathrm{dX} / \mathrm{dt}$.

\section{References}

[1] Joo, S. K., Kim, J. C., \& Liu, C. (2007, Aug.). Empirical analysis of the impact of 2003 blackout on security values of U.S. utilities and electrical equipment manufacturing firms. IEEE Transactions on Power Systems, 22(3).

[2] Lai, L., Zhang, H. T., Lai, C. S., Xu, F. Y., \& Mishra, S. (2013, July). Investigation on July 2012 Indian Blackout. Proceedings of the International Conference on Machine Learning and Cybernetics.

[3] Kundur, P. (1994). Power System Stability and Control (pp. 914-922). New York: McGraw-Hill.

[4] Abniki, H., Esfahani, A. S., Razzaghi, R., \& Nabavi-Razavi, M. T. (2010). Precise analysis of power swing effects on distance relay zones.

[5] Haner, J. M., Laughlin, T. D., \& Taylor, C. W. (1986, April). Experience with the R-RDOT out-of-step relay. IEEE Transactions on Power Delivery, 1(2), 35-39.

[6] Jafari, R., Moaddabi, N., Eskandari-Nasab, M., Gharehpetian, G. B., \& Naderi, M. S. (2014, June). A novel power swing detection scheme independent of the rate of change of power system parameters. IEEE Transactions on Power Delivery, 29(3).

[7] Nayak, P. K., Pradhan, A. K., \& Bajpai, P. (2013, April). A fault detection technique for the series-compensated line during power swing. IEEE Transactions on Power Delivery, 28(2).

[8] Lotfifard, S., Faiz, J., \& Kezunovic, M. (2010, January). Detection of symmetrical faults by distance relays during power swings. IEEE Transactions on Power Delivery, 25(1).

[9] Pahlevan, A., \& Sadeh, J. (2011). A new method to prevent distance protection from operating due to power swing. Proceedings of the International Conference on Advanced Power System Automation and Protection.

[10] Pang, C., \& Kezunovic, M. (2010, October). Fast distance relay scheme for detecting symmetrical fault during power swing. IEEE Transactions on Power Delivery, 25(4).

[11] Torres, S., Esponda, H., Andrade, M., Vázquez, E., Paternina, M. R. A., Zamora, A., \& Ramirez, J. M. (2016). Unblocking function of distance relay during power swing based on modal analysis. Proceedings of the IEEE PES Transmission \& Distribution Conference and Exposition - Latin America (PES T\&D-LA). 
[12] Tekdemir, I. G. \& Alboyaci, B. (2016). A novel approach for improvement of power swing blocking and deblocking functions in distance relays. IEEE Transactions on Power Delivery, 32(4).

[13] Kumar, J., \& Jena, P. (2017). Detection of fault during power swing using superimposed negative sequence apparent power based scheme. Proceedings of the 2017 6th International Conference on Computer Applications in Electrical Engineering-Recent Advances (CERA).

[14] Shalini, S. R., \& Sharma, A. (2017). A power and voltage-angle based index for distinguishing symmetrical fault from stable power swing. Proceedings of the 7th International Conference on Power Systems (ICPS).

[15] Patel, B., \& Bera, P. (2018, December). Detection of power swing and fault during power swing using Lissajous figure. IEEE Transactions on Power Delivery, 33(6).

[16] Patel, T. K., Mohanty, S. K., \& Mohapatra, S. (2017). Fault detection during power swing by phase difference technique. Proceedings of the International Conference on Innovations in Power and Advanced Computing Technologies.

[17] Hari, V., Deepa, S. K., \& Savier, J. S. (2018). Phasor measurement based fault detection and blocking/de-blocking of distance relay under power swing. Proceedings of the 2018 International CET Conference on Control, Communication, and Computing (IC4C).

[18] Paithankar, Y. G., \& Bhide, S. R. (2003). Fundamentals of Power Systems Protection (p. 144). India: Prentice Hall.

[19] Blumschein, J., Yelgin, Y., \& Juan, C. (2015). Power swing during fault conditions - Blackout analysis and avoidance. ProRelay.
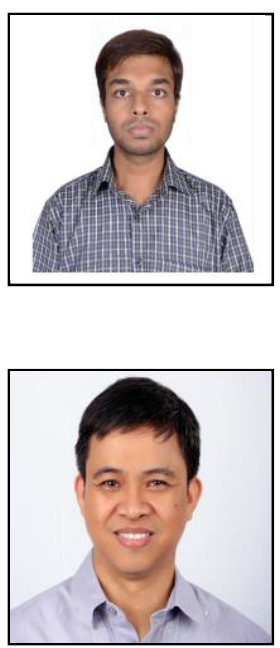

Aldrich Zeno received the BTech (hons) in electrical and electronics engineering from Vellore Institute of Technology, Vellore, India in 2012; the ME in power systems engineering from College of Engineering Guindy, Anna University, Chennai, India in 2014 and pursuing the PhD in University of the Philippines Diliman. His interests include power swing, fault analysis, transients and switchgear.

Jordan Rel Orillaza received the B.S.E.E. and M.S.E.E. degrees in electrical engineering from the University of the Philippines, Diliman, in 1996 and 2003, respectively, and the Ph.D. degree in electrical engineering from the University of Canterbury, Christchurch, New Zealand. His interests include flexible ac transmission systems modelling and power-quality studies. 